\title{
Integrating the European Securities Settlement
}

\author{
Torsten Schaper \\ Goethe-University Frankfurt, Chair of e-Finance, Grüneburgplatz 1, \\ 60323 Frankfurt, Germany \\ schaper@wiwi.uni-frankfurt.de
}

\begin{abstract}
The cross-border securities settlement in Europe is still said to be highly inefficient. One main reason can be seen in technical barriers between the different domestic settlement systems. Beside efforts to implement industryspecific communication standards an integration of the different settlement systems is necessary. The CSD-link model, the hub and spokes model, and the European CSD model aim to integrate European securities settlement. They have in common that they address the problem of interlinkage of national Central Securities Depositories and differ essentially in the way of achieving integration. These models are evaluated from a macro-economic perspective considering transaction costs, risks, and the integration of the cross-border securities settlement process.
\end{abstract}

Keywords: Financial Markets, Financial Institutions, Financial Intermediation, Securities Settlement, Integration, Standards.

\section{Introduction}

Trading on securities markets increases significantly. This means that not only more transactions need to be settled, but more of these transactions need cross-border settlement. Especially due to the increasing use of complex derivatives composed of assets from different trading venues. Trading activity, market liquidity, and capital market growth depend on safe and efficient trading and settlement systems. The importance of an efficient securities settlement system (SSS) lies in the safer transfer of ownership of assets against payment. In context of the financial crisis some of these systems had to handle enormous peaks in volumes: for instance the settlement system of UK (Euroclear) had to handle 1.6 million transactions on 15 October 2008, double the average monthly volume [15]. Such systems have to minimise the risks involved in the securities transactions and generate costs that do not hinder the intention to trade securities. Besides a changing regulatory environment technological innovations are fundamental catalysts behind the past and the future changes in securities settlement. Link Up Markets, the Single Settlement Engine (SSE), and TARGET2Securities (T2S) are heavily discussed technical platforms that aim to achieve the integration of securities settlement in Europe. Until now little attention has been given to the issue of integration of European cross-border securities settlement.

As far as the author knows, only Kröpfl [19] has evaluated different models for the integration of securities settlement. The aim of this paper is to show the technical 
barriers in securities settlement, emphasise the importance of an industry specific communication standard, and to introduce models for technical integration. These models are compared using an evaluation framework considering transaction costs, risks, and integration of the settlement process.

The paper is organised as follows. First the status quo of European clearing and settlement is presented. In the following section the technical barriers in the securities settlement are presented. Then the role of communication standards for the interation of securities settlement are stated and different models and recent approaches for the integration of European settlement are introduced and discussed. In the following the presented approaches are evaluated. The paper closes with a conclusion.

\section{Clearing and Settlement of Securities Transactions}

Clearing and settlement are required after two parties have decided to transfer the ownership of a security. Clearing and settlement services deal with the execution of a trade. The purpose of clearing is the efficient handling of risks inherent to concluded, but still unfulfilled contracts. Clearing confirms the legal obligation from the trade. It involves the calculation of mutual obligations of market participants and determines what each counterpart receives. Central counterparty (clearing) is not included in the definition of clearing. A central counterparty (CCP) is an entity that interposes itself between the transactions of the counterparties in order to assume their rights and obligations, acting as a buyer to every seller and as a seller to every buyer. The original legal relationship between the buyer and the seller is thus replaced by two new legal relationships. The CCP thus absorbs the counterparty risk and guarantees clearing and settlement of the trade [31]. Subsequent to the clearing stage the second operation is settling a trade. Settlement is the exchange of cash or assets in return for other assets or cash and transference of ownership of those assets and cash. A Central Securities Depository (CSD) is the organisation that performs these functions.

Compared with the US, the settlement industry in Europe is fragmented. Settlement in Europe shows its origins in a patchwork of national systems. At the national level, the consolidation has taken place and in most countries only one CSD has prevailed [16]. Domestic settlement systems are efficient within the national boundaries. The costs per transactions in domestic settlement are as expensive as in the United States, but European CSDs realise higher margins [2004]. In contrast, the settlement of cross-border transactions in Europe is not efficient because of various barriers [29]. The main reason for the fragmented European settlement industry is that securities were traded at national level, partly as result of the existence of different currencies. As result, several CSDs at the European level continue to coexist and only recently consolidation has taken place. In the EU the number of settlement engines declined from 23 in 1999 to 18 in 2004 [13].

Recently the European Code of Conduct for Clearing and Settlement is affecting the post-trade industry. The Code is a voluntary self-commitment and follows to a number of principles on the provision of post-trading services for cash equities. The intention is to establish a strong European capital market and to allow investors the choice to trade any European security within a consistent, coherent, and efficient European framework. The aim of the Code of Conduct is to offer market participants 
the freedom to choose their preferred provider of services separately at each layer of the securities trading value chain and to make the concept of cross-border redundant for transactions between EU member states. The implementation of the Code consists of three phases, implementation of price transparency, access and interoperability, and service unbundling. It was implemented by the end of 2007 [14]. The guidelines defined for access and interoperability provide the basis for the development of links between respective service providers. In total, more than 80 requests for access and interoperability can be counted [28]. Until now these request have not concluded in new connections of post-trade infrastructures.

\section{Technical Barriers in Securities Settlement}

SSSs are critical components of the infrastructure of global financial markets. A financial or operational problem in any of the institutions that perform critical functions in the settlement process or at a major user of a SSS could result in significant liquidity pressures or credit losses for other participants. Any disruption of securities settlements has the potential to spill over to any payment system used by the SSS or any payment system that uses the SSS to transfer collateral. In the securities markets themselves, market liquidity is critically dependent on confidence in the safety and reliability of the settlement arrangements. Traders will be reluctant to trade if they have significant doubts as to whether the trade will in fact settle or not [3]. In the 27 European countries mainly one domestic CSD has prevailed. Therefore, different channels for the settlement of cross-border transactions coexist and the usage of additional intermediaries is needed for the settlement of these transactions. The usage of intermediaries increases the complexity of the process. These intermediaries increase risks, cause higher transaction costs (due to multiple IT-systems), and generate additional costs in the back-office. The national settlement systems operate on a variety of non standardised platforms. This implies differences in IT and interfaces that add costs to cross-border settlement by requiring a higher level of manual input. Connection and messaging protocols vary from one SSS to another and different rules of transfer and product definitions exist. Differences in reporting requirements between systems also increase the costs. The additional costs arise, because institutions have to invest in understanding the concerning technologies and in multiple back-office interfaces to communicate with all necessary systems, with a need for additional staff to understand and support the various arrangements. On an individual level, the technical difficulties are manageable, but the wish to avoid multiple linkages and the burden of following numerous rules and rule changes are key drivers in the use of local custodians and agents. The European Central Securities Depositories Association (ECSDA) has drafted a set of standards for communication between CSDs to support cross-border settlement [9]. In this context there is also a need for the adoption of an EU-wide protocol, defining message formats between systems and their members [16]. According to the second report on European clearing and settlement, national differences in the IT and interfaces should be eliminated by a protocol defined by SWIFT and the Securities Market Practice Group. Once defined, the protocol should be adopted by the Eurosystem in respect of its operations [17]. 


\section{Technical Integration of European Securities Settlement}

The interlinkage of the different SSSs represents a challenge to achieve an efficient and integrated European financial market. The integration can be achieved by the usage of technical standards, industry standards, or by a further going integration via the usage of central services or applications (see figure 1).

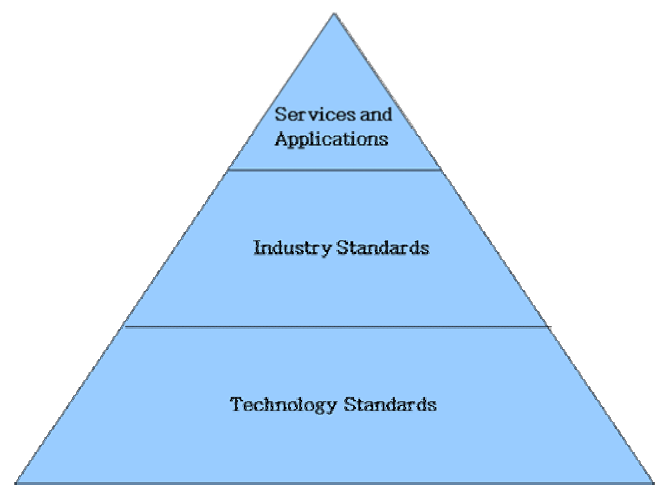

Fig. 1. Levels of integration [2]

\subsection{Technology Standards and Industry Standards}

Securities messaging and processing arrangements have developed in an uncoordinated fashion, sponsored by particular trading platforms and national arrangements for posttrade processing. Non-electronic trading has been converted into firm-specific order and trading formats for electronic processing. There has been diversity between different electronic platforms, thus equity trades have been recorded using different conventions in different countries. Even within financial centres different conventions for different markets have established. Different providers of security processing services have also developed own procedures [25]. Over recent years, the industry has developed generic procedures that can be used across trading and post-trading, notably the Financial Information eXchange (FIX) protocol and the Message Types (MT) for posttrade messages, promoted by SWIFT. Nonetheless, these formats are not fully standardised. With a large number of local variations they are applied across systems and between firms. Moreover, they are difficult to update. Changes in these standards can require wide-ranging adjustments to computer systems and business processes by financial firms, because implementation varies widely and any change in business relationship, e.g. obtaining transaction management services from a new supplier, involves very substantial IT system costs. The adoption of more fully harmonised and simplified standards will reduce these switching costs [25]. Future development of straight through processing will be facilitated by the use of data formats based on extensible mark up language (XML). XML allows richer message content, supports browser based interaction and communication, and are hence fully software and hardware independent. XML documents are more transparent and human readable. Moreover, XML 
is well suited to incorporate future changes in technology and processing arrangements [1]. XML standards are well suited to support distributed processing. With XML standards and distributed processing it is not necessary to create centralised processing hubs in order to facilitate EU-wide securities processing. Instead, almost all aspects of securities processing can be handled through a decentralised computing network [25]. XML versions of FIX and the MT message formats have been developed. Specifically, the FIX protocol is contributing its expertise in the pre-trade and trade execution domain while SWIFT is providing post-trade domain expertise. The aim should be to migrate the securities industry to a standardised use of XML, ensuring interoperability across financial industry. In 2005, SWIFT led the industry-wide project to help to define the communication protocol which was identified as the most effective solution for the removal of the national differences in IT. One of the key recommendations was that all securities market infrastructures and participants involved in European clearing and settlement area should support the use of ISO 15022 and 20022 standards. SWIFT is working with the European infrastructural community to identify the processes and activities that they support in the clearing, settlement, and asset servicing market spaces. These activities have been mapped against ISO messages and there is an ongoing process of identifying the gaps [1]. According to the final protocol recommendation it should be mandatory for all infrastructures and participants that are active in European clearing, settlement, and asset servicing of cash equities, fixed income, and listed funds to support the use of ISO 15022 and 20022 standards [1].

The establishment of such an industry standard can be only a first step in the integration of the European financial markets. In the following different models that go further are introduced. These models go back to communication models and general e-Business architectures [2][30] and have in common that such industry standards are essential for further integration.

\subsection{CSD-Link Model}

The establishment of links between all CSDs is one possibility to improve the settlement of cross-border transactions. These links allow the investor to take ownership of foreign securities through its domestic CSD. Bilateral links could reduce direct and indirect settlement costs, because a participant does not have to pay for the membership in more than one CSD or pay an intermediary to grant access to the foreign market. The resulting network of CSDs is visualised in figure 2.

Such network is difficult to implement completely, given the high costs associated with the establishment of bilateral links and the current low use of most of these links [18]. The total costs of settlement (TC) by this interlinkage are high. Each of the $n$ CSDs has to establish a link (with costs of $\alpha_{i}$ ) to all other CSDs and continue to operate its own SSS $\left(\beta_{i}\right)$. Besides these fixed costs the variable costs $\left(\mathcal{E}_{i}\right)$ depending on the number of transactions $\left(\delta_{i}\right)$ need to be considered.

$$
T C=\sum_{i=1}^{n}(n-1) \cdot \alpha_{i}+\beta_{i}+\delta_{i} * \mathcal{E}_{i}
$$




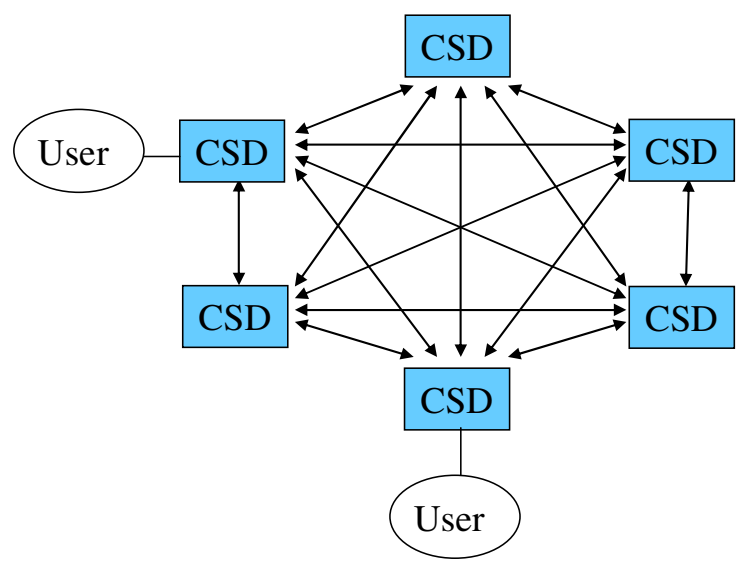

Fig. 2. CSD-link model [19]

The costs for CSD links are stated to range between 500,000 and 10,000,000 Euro [19][24]. Because of the 27 CSDs in Europe 702 links $(n *(n-1))$ would need to be established. This makes an investment of 351 to 7,020 million Euro (depending of assumed link costs) necessary to establish the network. However, the all-in savings are low, because the redundant infrastructure remains in place and the transaction costs would likely be high as each CSD has to open accounts in the CSDs of all counterparties [27].

\subsection{Hub and Spokes Model}

The hub and spokes model foresees a central hub that has the function to direct transactions to the national CSDs. Each CSD establishes one link to the central hub (see figure 3). The CSD remains the single point of entry for their users.

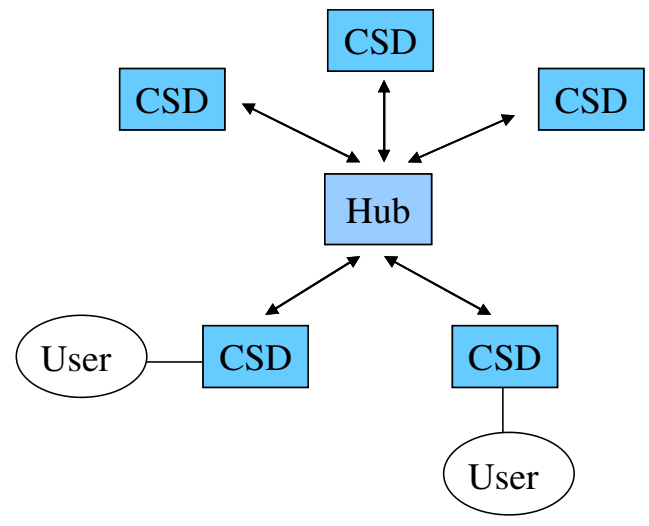

Fig. 3. Hub and spokes model 
Additional costs arise from the creation of the hub $(\gamma)$. On the other hand savings are achieved by reducing the number of links to $n$ (one link for each CSD to the hub).

$$
T C=\gamma+\sum_{i=1}^{n} \alpha_{i}+\beta_{i}+\delta_{i} * \mathcal{E}_{i}
$$

In the following, two recent approaches related to the hub and spokes model, Link Up Markets and T2S project, are introduced.

\subsubsection{Link Up Markets}

Link Up Markets is a joint venture by seven CSDs: Clearstream Banking Frankfurt, Hellenic Exchanges, Iberclear, Österreichische Kontrollbank, SIS SegaIntersettle, VP Securities Services and VPS. The aim is to establish a technical platform that is similar to the hub and spokes model. The idea is to overcome the hurdles and inefficiencies in the cross-border equities business by establishing a single cross-border operating organisation. Link Up Markets plans to deliver a central linkage to the national systems. The launch is planned for the first half of 2009. The CSDs still provide the single point of access for domestic and cross-border business [21]. The domestic institutions and infrastructure remain unchanged. The settlement takes place in the issuer CSD, which provides that regulatory requirements are met. Since CSDs are exclusively clients of the Link Up Markets, the CSD of choice is solely responsible for handling the relationship with its customers. The savings are expected to be derived from the fact that only one organisation is to implement and to manage the cross-border network. The market participants will instead continue to settle across borders via their domestic entry into this structure. The need to maintain several different access points stops. Each domestic CSD remains in its current state and function and all access points can still be used. Reduced interconnection costs are expected regarding negotiations, link processing, interfaces, synchronisation of systems, data formats, link contracts, liquidity requirements, and effective use of collateral. In addition, Link Up Markets will achieve network externalities leading to further cost savings shared by the whole community, as centralised linkage will help in standardising processes and practices [21[32]. While a bilateral link is too costly to be justified by the relatively small amount of transactions for a small CSD, a central link does not rule out the possibility of small players benefiting from economies of scale. Although the proposal to link the domestic systems does not lead to a substantial risk concentration in a single system and the safety or stability of systems shown in the domestic environment is not endangered. The platform provides a basis for further consolidation and integration of the European capital market, because the linkage of domestic systems increases the pressure to apply common technical standards, harmonised rules and regulations, identical tax treatment, and handling of country-specific taxes. The vision is to develop common operating standards and principles such as the simplification of crossborder corporate actions and consistent legal frameworks regarding the transfer of securities. This could start an evolutionary process and may spur the consolidation of the European settlement systems, because the platform could help national institutions to agree on uniform standards for securities settlement, rules, and regulations for automated securities lending and borrowing [32]. It also solves the complex bilateral links between all CSDs and thus help to align their work. The project adds another 
service layer to the settlement process of cross-border-transactions. It achieves integration by providing interoperability to continue the whole system of different national CSDs. The first step to achieve interoperability is to agree on standards, communication protocols, common operation methods, and practices. Link Up Market could act as a catalyst for standardisation.

\subsubsection{TARGET2-Securities}

On $7^{\text {th }}$ July 2006, the European Central Bank (ECB) issued a press release, stating that the Eurosystem was evaluating opportunities to provide efficient settlement services for transactions in central bank money, leading to the processing of both securities and cash settlement on a single platform through common procedures. The platform, called T2S, is the proposal to the CSDs to transfer their securities accounts to a common technical platform. The main benefits of this platform would be the reduction of settlement engines and therefore the reduction of costs for CSD-infrastructure and for custodians' back offices. Background of T2S is the technical debate about the best way to synchronise the delivery of securities with the cash payment. There is general agreement that the most efficient approach for both security and cash movements is to be managed by the same platform. In some countries this process is managed by the SSS, which determines when settlement takes place. As a result, the CSD effectively controls some payments across the books of the central bank: when the CSD determines that a transaction has settled, this causes the money to move on the books of the central bank. In other countries the central bank is unwilling to outsource control of central bank payments to another organisation. To maintain an integrated system, if the CSD cannot manage the money, the central bank has to manage the securities [28]. Then T2S is the only way to reach the integration of the settlement of securities and cash. The settlement of securities and cash would be realised within a single integrated platform. At the start of every day, participating CSDs would transfer their securities balances and outstanding transactions to T2S. During the day, T2S would settle these transactions and report to the CSDs at the end of the day. One consequence of T2S would be the separation of operation of settlement from the other functions performed by CSDs, such as asset servicing, asset financing, and provision of collateral. These other functions require access to real-time, intraday information on the securities balances held by participants in the systems, and the ability to control those balances. To realise this, a sophisticated linkage between T2S and the systems from the CSDs is required [6].

On $15^{\text {th }}$ January 2007 , the ECB presented details on the economic, technical, operational, and legal feasibility of T2S. According to the economic feasibility study of the ECB, T2S could reduce the average costs for domestic and cross-border securities settlement to $€ 0.28$ per transaction [7]. According to this study, the costs for domestic settlement in Europe range between $€ 0.45$ and $€ 2.30$ [7]. For the success of T2S the participation of all relevant CSDs is essential. The economic feasibility report assumes that all CSDs in the Euro area participate. If the participation in T2S is not mandatory, the number of transactions could be significantly lower and the costs per transaction would increase significantly [28]. There are a number of details to be clarified, like supervision of the platform, governance, questions on competition, the effects on the private enterprise infrastructure, and alternatives to integrate the different national infrastructures [20]. On $8^{\text {th }}$ March 2007, the Governing Council of the 
ECB has concluded that it is feasible to implement T2S and therefore decided to go ahead with the next phase of the project, namely the definition of user requirements on the basis of market contributions. These requirements were approved by the Governing Council. Most of the CSDs indicated participation and thus the Council decided in July 2008 to go on with the project [8].

\subsection{European CSD Model}

The European CSD is an integrated model to improve efficiency of the European securities settlement. The European CSD would be the only CSD providing settlement services for the European market (see figure 4).

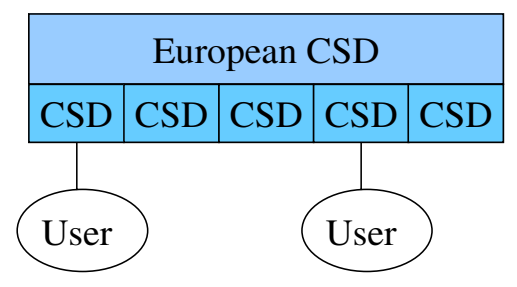

Fig. 4. European CSD

Also other operations performed by CSDs would be performed by a single CSD. It would lead to costs reduction, because only one integrated SSS would remain. Furthermore no CSD links would be needed anymore.

$$
T C=\beta+\delta * \varepsilon
$$

In addition costs reductions in back office of the users would be the result. The European CSD would also lead to an integrated and harmonised securities settlement, because all transaction would be managed within one single system. It must be considered that a central CSD could reduce competition in the settlement industry and could therefore also have adverse effects on market efficiency [29]. A well-known example for such a CSD is the Depository Trust Company (DTC) in the US. The DTC is providing settlement services for different US markets.

In the following, the Single Settlement Engine of the Euroclear Group is introduced as an example of an approach similar to an European CSD. Euroclear is forcing an integrated approach. Instead of achieving interoperability of the different national systems in Belgium, France, the Netherlands, Ireland, and the UK, Euroclear is implementing an integrated platform for securities settlement. The SSE is a practical harmonisation project not only providing integrated cash and securities settlement, but also an incorporated system for different European countries [10][5]. The SSE is the first major milestone in accomplishing Euroclear's objective to harmonise services on a consolidated processing platform, merging the five settlement platforms into one. Euroclear plans to save $€ 300$ million per year with the consolidation of the different settlement platforms, by market practise harmonisation, and by removing the barriers in the markets served by the Euroclear Group [10]. The users of the SSE operate as if they would act in a domestic market (see figure 4). 


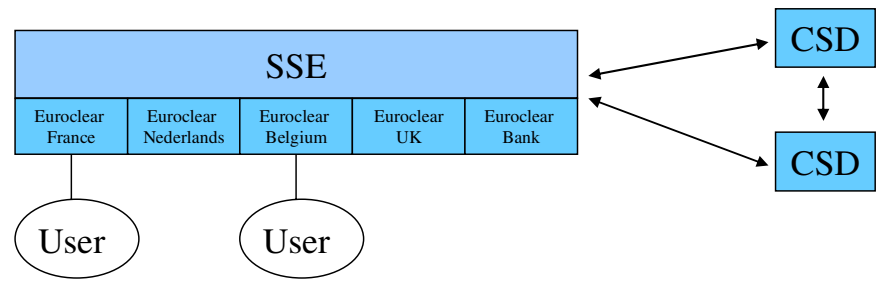

Fig. 5. Integration with the Single Settlement Engine

The next step in Euroclear's migration to a single platform is the launch of Euroclear Settlement for Euronext-zone Securities (ESES). Using the SSE as its foundation, ESES will serve as a single processing solution to process both domestic and cross-border fixed-income and equity transactions in the Belgian, Dutch, and French markets as if they were a single market. ESES was launched in France at the end of 2007, and was launched in Belgium and the Netherlands in the second quarter of 2008. The final consolidation of the platforms is aimed for 2010 [11]. Euroclear has announced to acquire the Nordic CSD and to extend the SSE to these markets (Finland and Sweden) as well [12].

\section{Evaluation of Models for Integration}

The total costs for settlement services are difficult to determine, because of the large number of factors, fees, risks etc. So far there exists no accepted study on the costs and fees of trading and post-trading in Europe. The European Commission has assigned OXERA [26] to conduct a study on costs and prices in European trading and post-trading. The results are still pending. The costs of the SSSs consist of the total costs of ownership and the processing costs [23]. Due to the large number of European CSDs the costs for the redundant SSSs are high. Furthermore, the processing costs of a transaction crossing different systems are respectively higher than for an inner-system transaction. International technical standards can increase the interoperability of SSSs and thus reduce the costs of cross-border and cross-system transaction [19]. Transaction costs form a very important criterion for the evaluation of the presented models and approaches. However in evaluation of efficiency of securities settlement, transaction costs and settlement risks are often not considered properly. Transaction costs can either arise from the provision or the usage of an institution. The first needs to be considered if institutional arrangements are changed. The focus of the following evaluation lies on these costs. The latter costs consist of the costs of the usage of the institution [19]. Beside transaction costs the risk needs to be considered for the evaluation. Major parts of the transaction risk have nearly been eliminated by the synchronisation of payment and securities delivery, but risk still remains [15]. Risks are often not considered since the respective risks rarely arise [23]. At least it is obvious that these risks need to be considered since the crash in October 1987 [4] and the current global financial crisis [15]. Furthermore, the time for the implementation, the integration of the settlement process, the integration of other 
post-trade services, and the technical integration have to be taken into consideration. The main difference of the presented models is the interlinkage of the CSDs. These models and current approaches differ essentially. They have in common that they improve the interoperability of SSSs and thus reduce the costs for development, support, mapping, and maintenance of communication.

The CSD-link model reaches integration, but makes investments in infrastructure necessary. The hub and spokes model reaches further integration and reduces the number of CSD-links, but does not reduce the number of national systems. T2S shows an advanced integration of the settlement process by integrating the cash settlement. For market participants these two models mean one more intermediary in the process of cross-border settlement. But the approaches T2S or Link Up Markets could mean a first step towards further consolidation and integration. The model of the European CSD is more comprehensive. By integrating different SSSs into one central platform it aims to reduce the number of SSSs and thus achieves a harmonisation of settlement and custody services. The aim of this model is the creation of a domestic settlement process within Europe. The approaches of T2S and the European CSD have in common that they make fundamental investments in a central IT-platform necessary. The implementation of such complex projects takes a long time. But such a centralised platform could perform an integrated infrastructure and support the process of a harmonised and integrated European securities settlement.

Table 1 shows the key findings of the comparison of the different models and approaches. The comparison was made by giving a score for the single criteria from a macro-economic perspective. The scores range from ++ (very good) to -- (very bad). A more detailed analysis is included in the appendix.

Table 1. Comparison of models and approaches to improve securities settlement in Europe

\begin{tabular}{|l|c|c|c|c|}
\hline & $\begin{array}{c}\text { CSD-link } \\
\text { model }\end{array}$ & $\begin{array}{c}\text { Link Up } \\
\text { Markets }\end{array}$ & T2S & European CSD \\
\hline Settlement risk & 0 & 0 & $+(+)$ & $+(+)$ \\
\hline Settlement costs & -- & - & + & + \\
\hline Implementation time & + & ++ & - & -- \\
\hline Technical integration & 0 & + & ++ & ++ \\
\hline $\begin{array}{l}\text { Integration of cross- } \\
\text { border settlement }\end{array}$ & - & 0 & + & ++ \\
\hline $\begin{array}{l}\text { Integration of other } \\
\text { post-trade services }\end{array}$ & + & + & - & + \\
\hline $\begin{array}{l}\text { Integration of cash } \\
\text { settlement }\end{array}$ & - & - & ++ & + \\
\hline
\end{tabular}


- Due to the settlement within one single integrated platform, the settlement risk on T2S and the European CSD are significantly lower than in the other approaches. T2S integrates cash and securities settlement on one platform. An European CSD could also integrate cash settlement (if the central banks are willing to). This integration reduces the settlement risk essentially.

- The CSD-link model assures interoperability by the interlinkage of the CSDs. The all-in savings are low, because the redundant infrastructure remains in place. The hub and spokes model and the recently discussed approaches T2S and Link Up Markets reach further integration, but do not reduce the number of national systems for settlement. For market participants these concepts mean one more intermediary in the process of cross-border settlement.

- The interlinkage of all CSDs is fastest to realise with Link Up Markets. For T2S or the European CSD the development of a new platform is necessary.

- The best technical integration is achieved by the introduction of one single platform. The integration of cross-border settlement can be achieved best within one platform.

- The integration of other post-trade services can be achieved best if settlement and related custody services are not separated. The only approach that separates these services is T2S. The European CSD provides an integrated European securities settlement in one central SSS. The aim of such a system is the creation of a domestic settlement and custody process for the markets of the European Union.

The presented models show that by improving the interoperability of SSSs cost reductions can be achieved. Centralised approaches share that they make fundamental investments in a central IT-platform necessary and that the implementation of such complex projects takes a long time. Still such a platform could perform an integrated infrastructure and support the process of a harmonised and integrated European securities settlement.

\section{Conclusion and Outlook}

In the last years integration and consolidation has taken place, but the European settlement is still a fragmented industry, showing inefficiencies in cross-border securities settlement. The introduction of communication standards for improving the interoperability can only be a first step for improving the integration. The interlinkage of the different domestic SSSs represents a challenge in achieving an efficient and integrated European financial market. The CSD-link model assures interoperability by linking the domestic CSDs. The all-in savings are low, as the redundant infrastructure remains in place. The hub and spokes model and the recently discussed approaches T2S and Link Up Markets reach further integration, but do not reduce the number of domestic systems for settlement. For the market participants these concepts mean one more intermediary in the process of cross-border securities settlement. Yet these platforms could mean a first step towards further consolidation and integration. A different approach was chosen by the Euroclear Group with the SSE, integrating different SSSs into one central platform. The advantage of this approach is the reduction of SSSs and the harmonisation of settlement services within the group. The aim of this platform is to create a domestic settlement and custody process for the markets of the 
group. The main disadvantage is that it is limited to selected markets. The extension to other markets is difficult due to the heterogeneous settlement industry. By improving the interoperability of SSSs a reduction of costs can be achieved. Centralised approaches, as T2S and the European CSD, share that they require fundamental investments in a central IT-platform and that the implementation of such complex projects takes a long time. However, such a centralised system could perform an integrated infrastructure and support the process of a harmonised and integrated European securities settlement. It is interesting that the different central approaches of Link Up Markets, T2S, and SSE are followed at the same time. Euroclear (building up the SSE) and Clearstream Banking (involved in Link Up Markets) as the most important European CSDs have announced to support the further development of T2S.

Acknowledgments. The author gratefully acknowledges the support of the E-Finance Lab, Frankfurt for this work.

\section{References}

1. Adams, D.: Elimination of Giovannini Barrier One, SWIFT, Final Protocol recommendation (2006)

2. Albrecht, C., Dean, D., Hansen, J.: Marketplace and technology standards for B2B e-commerce: progress, challenges, and the state of the art. Information \& Management 42, $865-875$ (2005)

3. BIS. Recommendations for Securities Settlement Systems', Consultative Report (January 2001)

4. Bernanke, B.S.: Clearing and Settlement during the Crash. The Review of Financial Studies, 133-151 (1990)

5. Cox, P., Simpson, H., Jones, L.: The Future of Clearing and Settlement in Europe. Corp. of London City Research Series (7) (2005)

6. ECB, TARGET2-Securities, Frankfurt: European Central Bank (2006)

7. ECB, TARGET2-Securities - Economic Feasibility Study, 2nd TARGET2-Securities meeting with market participants (2007)

8. ECB. Press Release 17.07.2008: Launch of the TARGET2-Securities project (2008), http: / / www. ecb. int/press/pr/date/2008/html/pr080717.en.html (accessed July 18, 2008)

9. ECSDA, Cross-Border Clearing and Settlement through CSD Links, report by ECSDA WG3 (2006)

10. Euroclear, Delivering domestic market for Europe, Bruessels: Euroclear Group (2002)

11. Euroclear (2007), http: / / www . euroclear. com (accessed December 10, 2007)

12. Euroclear. Press Release 02.06.2008: Nordic CSD to join the Euroclear Group (2008)

13. European Commission, Draft working document on Post-Trading (2006)

14. FESE, EACH, and ECSDA, The European Code of Conduct for Clearing and Settlement (2006)

15. Francotte, P.: Rising to the challenge of the crisis and change. The view from the CEO of Euroclear (14), 1-8 (2009)

16. Giovannini Group, Cross-Border Clearing and Settlement Arrangements in the EU (2001)

17. Giovannini Group, Second Report on EU Clearing and Settlement Arrangements (2003)

18. Kauko, K.: Interlinking securities settlement systems: A strategic commitment? Journal of Banking \& Finance 31, 2962-2977 (2007) 
19. Kröpfl, S.: Effizienz in der Abwicklung von Wertpapiergeschäften. Wissenschaftlicher Verlag, Berlin (2003)

20. LIBA, ESF, and ICMA, Letter to the ECB on Securities Sector Representation in T2S Committees (2007),

http: / /www.icma-group.org/market_practice/Advocacy/

clearing_and_settlement/target2-securities.html (accessed April 27, 2007)

21. Link Up Markets. Press Conference, Madrid (April 2, 2008),

http: / / www . Iinkupmarkets.com/pdf / LinkUpMarkets-

PressConferencePresentation.pdf (accessed July 3, 2008)

22. NERA Economic Consulting, The direct costs of clearing and settlement: an EU-US comparison, Corporation of London City Research Series, No. 1 (2004)

23. Neumann, D., Lattemann, C.: Clearing and Settlement im Wandel - Eine Perspektive für den europäischen Wertpapierhandel. Zeitschrift für die gesamte Kreditwirtschaft (2002)

24. Norman, P.: The limits to inteoperability. Speed 1, 23-26 (2006)

25. Milne, A.: Standard setting and competition in securities settlement, Bank of Finland, Discussion Paper 2005, No. 23 (2005)

26. Oxera. Methodology for monitoring prices, costs and volumes of trading and post-trading activities (July 2007), http: / / ec .europa .eu/internal_market/financialmarkets / docs / clearing/oxera_study_en.pdf(accessed May 7, 2009)

27. Park, D., Rhee, C.: Building a Settlement Infrastructure for the Asian Bond Markets: Asiasettle. In: Asia's Debt Capital Markets, pp. 291-314. Springer, New York (2006)

28. Schaper, T.: Trends in European Cross-Border Securities Settlement - TARGET2Securities and the Code of Conduct. In: Veit, D.J. (ed.) FinanceCom 2007. LNBIP, vol. 4, pp. 50-65. Springer, Berlin (2007)

29. Schmiedel, H., Malkamaki, M., Tarkka, J.: Economies of scale and technological development in securities depository and settlement systems. Journal of Banking \& Finance 30, 1783-1806 (2006)

30. Weitzel, T., Beimborn, D., König, W.: A Unified Economic Model of Standard Diffusion: The Impact of Standardization Cost, Network Effects, and Network Topology. MIS Quarterly 30, 489-514 (2006)

31. Wendt, F.: Intraday Margining of Central Counterparties: EU Practice and a Theoretical Evaluation of Benefits and Costs. Netherlands Central Bank, Amsterdam (2006)

32. Werner, S.: Interoperability and interlinking: the way forward for the C\&S industry. Frankfurt Voice (January 10, 2003)

\section{Appendix}

Table 2. Detailed comparison of models and approaches to improve securities settlement

\begin{tabular}{|l|c|l|c|l|}
\hline & \multicolumn{2}{|c|}{ CSD-link model } & \multicolumn{1}{c|}{ Link Up Markets } \\
\cline { 2 - 5 } Settlement risk & 0 & $\begin{array}{l}\text { Unchanged. The systemic risk } \\
\text { remains low due to the redun- } \\
\text { dant infrastructure. }\end{array}$ & 0 & $\begin{array}{l}\text { Unchanged. The systemic risk } \\
\text { remains low due to the redun- } \\
\text { dant infrastructure. }\end{array}$ \\
\hline Settlement costs & -- & $\begin{array}{l}\text { Redundant infrastructure remains in } \\
\text { place, costly links or agents banks } \\
\text { are used for cross-border transac- } \\
\text { tions. }\end{array}$ & $\begin{array}{l}\text { Costs savings due to reduced inter- } \\
\text { linkage costs; the costs for the } \\
\text { redundant settlement systems } \\
\text { remain; additional costs for the } \\
\text { establishment of the hub. }\end{array}$ \\
\hline
\end{tabular}


Table 2. (Continued)

\begin{tabular}{|c|c|c|c|c|}
\hline Implementation time & + & $>1$ year. & ++ & $<1$ year. \\
\hline Technical integration & 0 & $\begin{array}{l}\text { Domestic integration, no integration } \\
\text { of cross-border processes. }\end{array}$ & + & $\begin{array}{l}\text { Improved interlinkage of participat- } \\
\text { ing entities. }\end{array}$ \\
\hline $\begin{array}{l}\text { Integration of cross- } \\
\text { border settlement }\end{array}$ & - & No integration. & 0 & $\begin{array}{l}\text { No integration, but harmonisation } \\
\text { of processes planed. }\end{array}$ \\
\hline $\begin{array}{l}\text { Integration of other } \\
\text { post-trade services }\end{array}$ & + & $\begin{array}{l}\text { Integration of domestic settlement } \\
\text { and custody. }\end{array}$ & + & $\begin{array}{l}\text { Integration of domestic settlement } \\
\text { and custody. }\end{array}$ \\
\hline \multirow[t]{3}{*}{$\begin{array}{l}\text { Integration of cash } \\
\text { settlement }\end{array}$} & - & No integration. & - & No integration. \\
\hline & \multicolumn{2}{|r|}{ TARGET2-Securities } & \multicolumn{2}{|r|}{ European CSD } \\
\hline & Score & Description & Score & Description \\
\hline Settlement risk & $+(+)$ & $\begin{array}{l}\text { Legal and credit risk are re- } \\
\text { duced significantly due to the } \\
\text { integration of cash and securi- } \\
\text { ties settlement within one plat- } \\
\text { form; no media breaches in } \\
\text { cross-border transactions. The } \\
\text { systemic risk is higher due to } \\
\text { the concentration in one central } \\
\text { platform instead of decentral- } \\
\text { ised platforms. }\end{array}$ & $+(+)$ & $\begin{array}{l}\text { Legal and credit risk are re- } \\
\text { duced significantly due to the } \\
\text { possibility of integration of cash } \\
\text { and securities settlement within } \\
\text { one platform; no media } \\
\text { breaches in cross-border trans- } \\
\text { actions. The systemic risk } \\
\text { remains low due to the redun- } \\
\text { dant infrastructure. }\end{array}$ \\
\hline Settlement costs & + & $\begin{array}{l}\text { Cost saving due to reduction of } \\
\text { settlement engines, links, and } \\
\text { intermediaries; but additional costs } \\
\text { for the new platform. }\end{array}$ & + & $\begin{array}{l}\text { Cost saving due to reduction of } \\
\text { settlement engines, links, and } \\
\text { intermediaries; but additional costs } \\
\text { for the new platform. }\end{array}$ \\
\hline Implementation time & - & 6 years planed. & -- & More than 6 years. \\
\hline Technical integration & ++ & $\begin{array}{l}\text { One integrated platform for cash } \\
\text { and securities for all markets. }\end{array}$ & ++ & $\begin{array}{l}\text { One integrated platform for all } \\
\text { markets. }\end{array}$ \\
\hline $\begin{array}{l}\text { Integration of cross- } \\
\text { border settlement }\end{array}$ & + & $\begin{array}{l}\text { Harmonised almost domestic Euro- } \\
\text { pean settlement process; Custody is } \\
\text { not integrated. }\end{array}$ & ++ & $\begin{array}{l}\text { Harmonised almost domestic Euro- } \\
\text { pean settlement and custody proc- } \\
\text { ess. }\end{array}$ \\
\hline $\begin{array}{l}\text { Integration of other } \\
\text { post-trade services }\end{array}$ & - & $\begin{array}{l}\text { Separation of settlement and cus- } \\
\text { tody. }\end{array}$ & ++ & $\begin{array}{l}\text { Integration of domestic and cross- } \\
\text { border settlement and custody. }\end{array}$ \\
\hline $\begin{array}{l}\text { Integration of cash } \\
\text { settlement }\end{array}$ & ++ & $\begin{array}{l}\text { Integration of cash and securities } \\
\text { settlement on one platform }\end{array}$ & + & $\begin{array}{l}\text { Integration of cash and securities } \\
\text { settlement on one platform is possi- } \\
\text { ble }\end{array}$ \\
\hline
\end{tabular}

